\title{
Cohort Study of Medical Cannabis Authorization and Motor Vehicle Crash- Related Healthcare Visits in 2014-2017 in Ontario, Canada
}

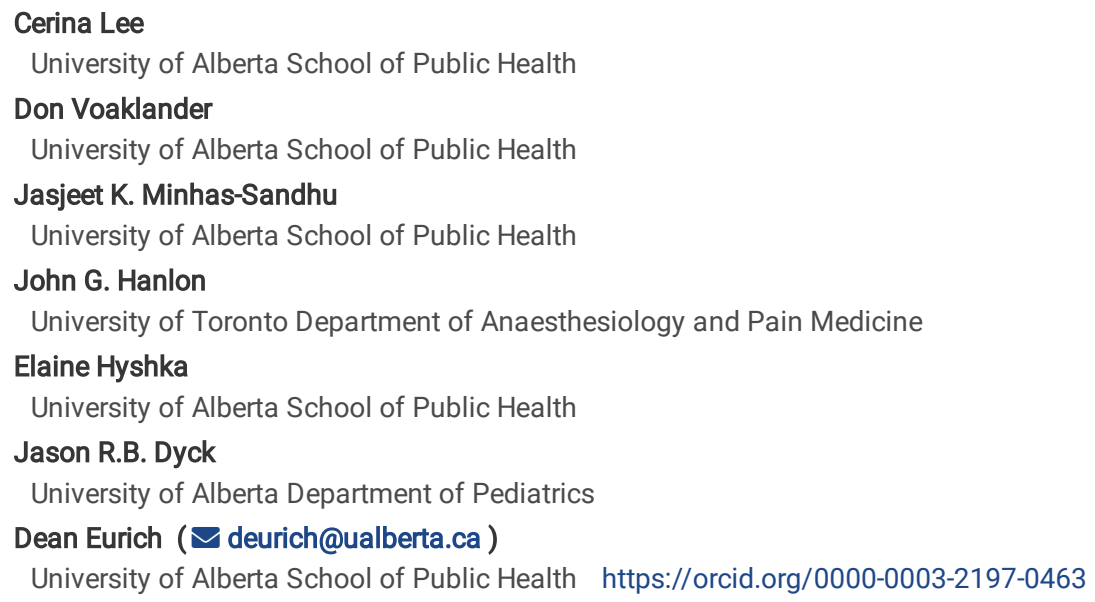




\section{Abstract}

Background: With increasing numbers of countries/jurisdictions legalizing cannabis, cannabis impaired driving has become a serious public health concern. Despite substantive research linking cannabis use with higher rates of motor vehicle crashes (MVC), there is an absence of conclusive evidence linking MVC risk with medical cannabis use. In fact, there is no clear understanding of the impact of medical cannabis use on short- and long-term motor vehicle-related healthcare visits. This study assesses the impact of medical cannabis authorization on motor vehicle-related health utilization visits (hospitalizations, ambulatory care, emergency room visits, etc) between 2014-2017 in Ontario, Canada.

Methods: A matched cohort study was conducted on patients authorized to use medical cannabis and controls who did not receive authorization for medical cannabis - in Ontario, Canada. Overall, 29153 adult patients were identified and subsequently linked to the administrative databases of the Ontario Ministry of Health, providing up to at least 6 months of longitudinal follow-up data following the initial medical cannabis consultation. Interrupted time series analyses was conducted to evaluate the change in rates of healthcare utilization as a result of MVC 6 months before and 6 months after medical cannabis authorization.

Results: Over the 6-month follow-up period, MVC-related visits in medical cannabis patients were 0.50 visits/10 000 patients ( $p=0.61$ ) and -0.31 visits/10 000 patients $(p=0.64)$ for MVC-related visits in controls. Overall, authorization for medical cannabis was associated with an immediate decrease in MVC-related visits of -2.42 visits $/ 10000$ patients $(p=0.014)$ followed by a statistically significant increased rate of MVC-related visits (+0.89 events/10,000 in those authorized medical cannabis) relative to controls in the period following their authorization $(p=0.0019)$. Overall, after accounting for both the immediate and trend effects, authorization for medical cannabis was associated with an increase of 2.92 events/10,000 ( $95 \% \mathrm{Cl} 0.64$ to 5.19$)$ over the entire follow-up period. This effect was largely driven by MVC-related emergency department visits $(+0.80$ events/10,000, $p<0.001)$.

Conclusions: Overall, medical cannabis authorization was associated with increased healthcare utilization as a result of a MVC, at the population level, in Ontario, Canada. These findings have public health importance and patients and clinicians should be fully educated on the potential risks. Continued followup of medically authorized cannabis patients is warranted to fully comprehend long-term impact on motor vehicle crash risk.

\section{Background}

Since 2001, Canadians have been allowed to legally possess cannabis for medical purposes with a health care provider's authorization(Alberta, 2017). With non-medical cannabis legalization in Canada and certain states in the United States, there is rising public concern about cannabis-impaired driving/driving under the influence of cannabis (DUIC)(Valleriani, 2017). Past fatality studies(Andrews et al., 2015; Callaghan et al., 2013; Fischer et al., 2016; Romano et al., 2017) resulting from motor vehicle crashes (MVC) suggest higher risk of MVC is associated with general cannabis consumption, however, there is a lack of robust evidence(Rogeberg and Elvik, 2016) surrounding MVC risk for medical cannabis users at the population level.

Previous research on cannabis use and MVC risk have shown mixed results -with a continued debate in the literature on whether or not this association is significant. Clinical studies have reported common physiological effects (both acute and long-term exposure of cannabis use) on the brain that have been found to impair driving ability(Neavyn et al., 2014; Ogourtsova et al., 2018; Wright and Metts, 2016). Evidence suggests that the risk of being involved in a motor vehicle crash increases approximately two-fold when a person drives immediately after smoking cannabis(Hartman and Huestis, 2013) and that acute cannabis intoxication may be associated with an increased MVC risk(Rogeberg and Elvik, 2016). In Canada, statistical data has shown that the percentage of fatally injured drivers from testing positive for cannabis, has generally increased over time(Foundation, 2018). Conversely, higher levels of tetrahydrocannabinol (THC) in the blood has been correlated with higher rates of MVC and impaired driving behaviors, but not at lower levels(Brubacher et al., 2019; Bonar et al., 2019). Further, other studies have shown a nonsignificant association between traffic accidents and cannabis use(Hostiuc et al., 2018; Hansen, 2018). In other jurisdictions where medical cannabis has been legalized (i.e. Colorado), an increased rate of MVCs has been reported; whereas the rate remained the same in states without cannabis legalization (Salomonsen-Sautel et al., 2014).

To address the evidence gap, research is needed on whether medical use of cannabis is associated with a higher risk of MVC. Although cannabis would be expected to have a similar potential for MVC in these patients, our study examines whether these medical cannabis patients represent a different subset of the cannabis using population with potentially different patterns of risk behaviors. While past studies on causal interpretation between medical cannabis impairment and motor vehicle crashes present mixed results - a majority of cohort studies are limited due to small sample sizes(Bonar et al., 2019; Ogourtsova et al., 2018), are outdated(Walsh and Mann, 1999; Asbridge et al., 2005), express high publication bias(Hostiuc et al., 2018); do not differentiate between medical and recreational cannabis(Azofeifa et al., 2015; Li et al., 2012; Masten and Guenzburger, 2014), rely heavily on self-reported measures(Richer and Bergeron, 2009), and have loss of participants to follow up over time(Callaghan et al., 2013) who are using medical cannabis.

Thus, we conducted a large cohort study of adults authorized to obtain medical cannabis - to assess whether medical cannabis use has any association on healthcare utilization due to MVC. In this paper, we hypothesized that there is an association between medical authorization for cannabis and MVC-related healthcare utilization in comparison to controls.

\section{Methods Study design}

A matched cohort study was conducted on patients authorized to use medical cannabis and controls who did not receive authorization for medical cannabis - in Ontario, Canada. 


\section{Study population}

Inclusion Criteria: All adult patients authorized for medical cannabis [inhaled (smoked or vaporized) or orally consumed (oils) cannabis] that attended specialized cannabis clinics in Ontario (Canada) between April 24, 2014 and March 31, 2017. These individuals were ${ }^{3} 18$ years of age, of any sex and ethnicity, and had received medical cannabis authorization for a variety of acute and chronic health conditions. Patients may choose to seek assessment for medical cannabis through the clinic via a self-referral or by a physician referral. The index date for each patient was the first recorded date of medical cannabis authorization at the clinics (Table 1).

\section{Exclusion Criteria:}

Adult patients who received medical cannabis authorization but were unable to be matched with at least one control, those who were non-eligible to Ontario Health Insurance Plan at baseline and those with invalid or duplicate identifiers were excluded. Patients who had less than 6 months administrative data before the index date and less than 6 months after, were also excluded. This restriction was to ensure we had sufficient health data to determine trends in health care utilization. Further, through sensitivity analysis, we excluded patients having less than 12 months data before the index date and less than 12 months data after.

\section{Matched Controls:}

Each authorized medical cannabis patient was matched at the time of the case index up to 3 controls based on age ( \pm 1 years), sex, Local Health Integration Network location, income quartile, and history of diabetes, heart disease, chronic obstructive pulmonary disease, asthma, cancer, musculoskeletal issues, neurological issues, pain, behavioral issues, fatigue, malnutrition, and metabolic disease based on any related ICD-9/10 codes within the previous 5 years. Matching was completed with replacement and thus an unauthorized patient could have been utilized for 1 or more authorized patients; however, in this study no control was used more than once in the analysis. To be considered as unauthorized, no record of a referral to a participating cannabis clinic was allowed. After matching, a pseudo-index date equal to the authorized patient was assigned so that the distribution of index dates is the same as the authorized patients.

\section{Data Source}

All data for both cannabis users and matched controls were obtained from the provincial administrative health databases collected and housed by Ontario's Institute for Clinical Evaluative Sciences. The ICES Data Repository consists of record-level, coded and linkable health data sets. It encompasses publicly funded administrative health services records for the Ontario population eligible for universal health coverage.

All adult patients seeking assessment at specialized cannabis clinics (between April 2014-March 2017) in Ontario, Canada were eligible. Informed consent was provided by the patient at the time of first intake, which allows data to be collected and used for clinical and research purposes. As part of the authorization and intake process, each patient seeking medical cannabis meets with a trained counselor who performs and initial assessment and collects relevant data. All patients must provide sociodemographic information and disclose their primary medical complaints that constitute their rationale for requesting a medical cannabis authorization. Following their initial intake interview, the patient is referred to a physician who makes their assessment based on the self-reported information, the patient's health record, and any additional assessments conducted by the physician. Initial referral to the clinics can be a self-referral by the patients or by a medical professional.

Overall, 29153 adult patients were identified and subsequently linked to the administrative databases of the Ontario Ministry of Health hospitalizations and emergency department visits providing up to at least 6 months of longitudinal follow-up data following the initial medical cannabis consultation. These data were provided by the ICES administrative databases in Ontario and all data was released as de-identified data. Research ethics approval was obtained from the University of Alberta Health Research Ethics Board (PRO 00083651) and Veritas Research Ethics Board (Ontario) (16111-13:21:103-01-2017).

\section{Outcomes}

All types of healthcare resources utilization that was related or potentially due to motor vehicle crashes was considered in this study. This included ICD-10 codes V40-V69 (Appendix 1); MVC related to buses were not included (V70-V79).

\section{Statistical analysis}

All data are expressed descriptively using means (standard deviations) or proportions as appropriate. To assess the effect of medical cannabis use on motor vehicle-related visits, interrupted time series (ITS) analyses assessed the trend in MVC in the 6 months before and 6 months after the authorization of cannabis. Each outcome was assessed in 30-day windows for each patient (i.e., total number of occurrences in the month). ITS analyses were conducted separately for patients authorized and those not authorized. Subsequently, the difference in motor vehicle-related visit outcomes between authorized and unauthorized patients was computed and modeled. By modeling the outcomes in this manner, a clear interpretation of effects can be observed: the trend in those authorized for medical cannabis; the trend in those not authorized; and the joint trend of those authorized relative to those unauthorized; as opposed by just relative effects between authorized and those unauthorized where the true drivers of any differences may be difficult to interpret. In addition, the 
overall absolute effects of medical cannabis authorization on MVC was calculated, which summarizes both the immediate level change (i.e., within a month) and change in trend over the 6 months with the multivariate delta method used to the construct $95 \%$ confidence intervals around the estimate(Zhang et al., 2009).

\section{Sensitivity analysis}

To assess the effect of longer exposure to medical cannabis on motor vehicle-related visits, we extended the follow-up to 12 months before the index date and after exposure by repeating the ITS analysis for all outcomes. However, it is important to note that this additional extension period led to the exclusion of patients who did not have sufficient data 12 months prior or 12 months after (or in the matched controls). As the number of patients included in this analysis was significantly smaller, we considered this as an exploratory analysis.

\section{Results}

In total, 29153 patients attended a cannabis clinic and provided consent. Of these patients, 9925 medically authorized cannabis patients having at least 6 months follow-up data before and after the index date were matched to 17732 controls (Figure 1). In each group, at least 2/3 of the patients were aged 60 years or less, and the majority were men (55\%). Musculoskeletal issues, anxiety, neurologic disorders, and asthma were the most predominant morbidities. Morbidities were well balanced between the two groups due to the matched study design although slightly fewer patients authorized for medical cannabis resided in a rural area ( $8 \%$ vs $10.7 \%$ ) and were more likely to have a history of anxiety ( $49 \%$ vs $24.3 \%)(p<0.001$ for each).

In the 6 months before authorization, there were 46 MVC-related health care visits/admissions per 10000 patients among those authorized for medical cannabis and 32 MVC-related health care visits/admissions per 10000 patients among those not authorized for medical cannabis (Table 2). Following medical cannabis authorization, MVC-related visits after 6 months was 0.50 visits per 10000 patients; and MVC-related visits in controls was - 0.31 visits per 10000 patients. Neither change was statistically significant ( $p=0.61$ and $p=0.64$, respectively) (Table 3 ); and also shown by the ITS analysis in the difference in monthly proportions of healthcare utilization between cases and controls (Figure 2). When comparing those authorized medical cannabis to controls, an immediate decrease in MCV -related visits of -2.42 events per 10,000 in those authorized medical cannabis was observed ( $p=0.0138$ ). This was followed by an increase of MVC-related visits of 0.89 events per 10,000 in those authorized medical cannabis (over the 6 months relative to controls), which was statistically significant $(\mathrm{p}=0.0019)$ (Table 3 ). After accounting for both the immediate and temporal effects, authorization of medical cannabis was associated with an increase of 2.92 events $/ 10,000(95 \% \mathrm{Cl} 0.64$ to 5.19$)$ over the entire follow-up period. Stratified analyses by type of MVC-related visit suggests that emergency department visits contributed to the majority of the difference observed between those authorized medical-cannabis compared to controls. Indeed, although no statistical difference was observed with respect to MVC-related hospitalizations immediately or during the follow-up or immediately in MVC-related emergency department visits, an increase of MVC-related emergency department visits was observed of 0.80 events per 10,000 in those authorized medical cannabis during the follow-up (over the 6 months relative to controls; $p=0.0001$ ) No clinically important differences were noted for either age or sex (Appendix 2 and 3).

In the 12 months before authorization, there were $121 \mathrm{MVC}$-related health care visits/admissions per 10000 patients among those authorized medical cannabis and 65 MVC-related health care visits/admissions per 10000 patients among those not authorized medical cannabis (Table 4). Following medical cannabis authorization, MVC-related visits in medical cannabis patients after 12 months was 0.33 visits per 10000 patients; and MVC-related visits in controls was 0.21 visits per 10000 patients - with neither change statistically significant $(p=0.70$ and $p=0.60$, respectively) (Table 5 ). However, when comparing those authorized medical cannabis to controls, MVC-related visits of -0.11 events per 10,000 in those authorized medical cannabis (over the 12 months relative to controls) was observed which was also not statistically significant $(p=0.56)$ (Table 5). After accounting for both the immediate and temporal effects, the absolute effect of medical cannabis authorization was a non-statistcially significant increase of 4.32 events/10,000 ( $95 \% \mathrm{Cl}-0.73$ to 9.37) over the entire 12-month follow-up period. Finally, no associations were observed with respect to either MVC-related hospitalizations or emergency department visits in stratified analyses when comparing those authorized medical cannabis to controls.

\section{Discussion}

This population-based study of patients authorized for medical cannabis showed an overall absolute increase in MVC-related visits of 2.92 per 10,000 people (compared to controls) within the first 6 months, which was largely driven by increases in MVC-related emergency department visits. However, no statistical differences in MVC-related healthcare utilization were observed in the subgroup of patients followed for up to 1 year, although the overall absolute effects were higher than the 6-month data (absolute events of 4.32 per 10,000 people). The clinical relevance of these findings at the individual level is unclear but may have important implications from a public health perspective.

The majority of previous studies of medical cannabis and MVC risk have shown inconsistent results. Certain studies report high correlation between medical cannabis/recreational cannabis use and MVC risk(Richer and Bergeron, 2009; Wright and Metts, 2016). Bonar et al. (2019) reported that DUIC behavior was higher in medical cannabis patients authorized for chronic pain than those in the general population of individuals who were reported to drive after the use of cannabis(Bonar et al., 2019). Recent Canadian reports on MVC and cannabis(Foundation, 2018; Alberta, 2017) indicate a general increase of fatally injured drivers who tested positive of cannabis from 2000 to 2015. Recent meta-analyses of epidemiological studies(Rogeberg and Elvik, 2016; Hartman and Huestis, 2013) including Li et al.(Li et al., 2012) also showed a significant increase of MVC risk as a result of cannabis consumption. Conversely, other metaanalyses report that the association between medical cannabis use and MVC risk is nonsignificant(Hostiuc et al., 2018) - and that only higher levels of cannabis were associated with higher MVC risk(Brubacher et al., 2019). Notably, other ITS studies(Hamilton et al., 2014) focused on recreational use and/or impairment without strictly focusing on solely medical use(Ogourtsova et al., 2018). Indeed, Masten et al.(Masten and Guenzburger, 2014) reported that 
medical cannabis laws may not necessarily be linked with increased MVC rates. Likewise, Neavyn et al.(Neavyn et al., 2014) reported the importance of distinguishing between medical cannabis and recreational cannabis to fully understand its effects on MVC-risk associated behavior. These discrepancies may explain the difference in outcomes associated with medical cannabis use and MVC risk among the various study populations.

The strength of our study is that it is currently the largest Canadian population-based study completed with population-based matched controls. However, our study is not without limitations. First, this is an observational study and potential spectrum bias is a concern as our cohort is based on patients who have individually sought authorization for medical cannabis. This population may not be representative of all individuals who are using cannabis for medical purposes but obtained it through other (legal or illegal) avenues. Second, although patients were authorized to use medical cannabis, we cannot ensure the products were consumed as authorized by physicians or if patients elected to use alternative agents than what was authorized. Moreover, there is no method of determining if medical cannabis was in a patient's system at the time of an MVC. Third, not all MVCs result in healthcare resource utilization and our data do not capture MVCs that did not result in injury or were less severe, thus, we only investigated major crashes resulting in healthcare utilization; not minor crashes.

\section{Conclusions}

Overall, this study suggests that an association between medical cannabis authorization and healthcare utilization as a result of MVC in Ontario medical cannabis users. We believe our findings can contribute ongoing evidence to frontline clinicians, health care administration, and federal/provincial governments regarding the current status of impaired driving and medical cannabis users in Ontario. Although some may consider the risk small, patients and clinicians need to be aware and educated on the potential risks associated with cannabis use. Users of medical cannabis should continue to use this medication with caution when interacting with their environments and follow all instructions concerning its use during the operation of motor vehicles.

\section{Abbreviations}

$\mathrm{ClHI}$ - Canadian Institutes of Health Research

ICES - Institute for Clinical Evaluative Sciences

ITS - interrupted time series

MVC - motor vehicle crashes

SPOR - Strategy for Patient-Oriented Research

THC - tetrahydrocannabinol

\section{Declarations}

\section{Ethics approval and consent to participate}

Research ethics approval was obtained from the University of Alberta Health Research Ethics Board (PRO 00083651) and Veritas Research Ethics Board (Ontario) (16111-13:21:103-01-2017). Informed consent was provided by the patient at the time of first intake, which allows data to be collected and used for clinical and research purposes. These data were provided by the Institute for Clinical Evaluative Sciences (ICES) administrative databases in Ontario and all data was released as de-identified data.

\section{Consent for publication}

This study made use of de-identified data from the ICES Data Repository, which is managed by the Institute for Clinical Evaluative Sciences with support from its funders and partners: Canada's Strategy for Patient-Oriented Research (SPOR), the Ontario SPOR Support Unit, the Canadian Institutes of Health Research and the Government of Ontario. The opinions, results and conclusions reported are those of the authors. No endorsement by ICES or any of its funders or partners is intended or should be inferred. Parts of this material are based on data and information compiled and provided by ClHI. However, the analyses, conclusions, opinions and statements expressed herein are those of the author, and not necessarily those of ClHI.

\section{Availability of data and materials}

The dissemination of data results to study participants and or patient organizations in this research project is not possible/applicable. The dissemination of data results to study participants and or patient organizations in this research project is not possible/applicable as the data is de-identified. Moreover, the data is not available as only the researchers authorized by ICES have access to the data.

\section{Competing interests}

JRBD is a former board member for a major cannbis company. JGH has worked as a paid advisor and speaker for Canadian Cannabis Clinics. JRBD has a financial interest in Aurora Cannabis Inc. DTE and JRBD hold a Mitacs Grant with Aurora as a partner. Mitacs is a national, not-for-profit organization that 
works with universities, private companies, and both federal and provincial governments, to build partnerships and administer research funding that supports industrial and social innovation in Canada. DTE does not have any past or present financial interest in the companies involved. CL, DV, JKMS, and EH have no conflicts of interest to declare. Moreover, the above mentioned entities, research funders and companies listed were not involved in any aspect of the design or write-up of the study and all analysis was performed independent from the funders and companies.

\section{Funding}

This study was funded by a Canadian Institutes of Health research Project grant (CIHR PS 159668) to DTE, JGH, EH, and JRBD.

\section{Authors' contributions}

DTE, JRBD, JGH, EH designed the study and DTE and JRBD acquired the data. DTE and JKMS analyzed the data. CL and DTE drafted the manuscript. All other authors revised it critically for important intellectual content and approved the final version to be published. All authors are accountable for the work and integrity of the work. The corresponding author and guarantor accepts full responsibility of the work and/or conduct of the study, had access to the data and controlled the decision to publish. DTE attests that all listed authors meet authorship criteria and that no others meeting the criteria have been omitted.

\section{Acknowledgments}

DTE affirms that the manuscript is an honest, accurate, and transparent account of the study being reported; that no important aspects of the study have been omitted; and that any discrepancies from the study as planned (and if relevant) have been explained.

\section{Tables}


Table 1

Characteristics of patients with six months follow-up before and six months after the index date included in interrupted time series analyses analysis $(n=27657 *)$

\begin{tabular}{|c|c|c|c|}
\hline Characteristic & $\begin{array}{l}\text { Unauthorized for medical cannabis } \\
(\mathrm{N}=17732)\end{array}$ & $\begin{array}{l}\text { Authorized for medical cannabis } \\
(\mathrm{N}=9925)\end{array}$ & p-value \\
\hline \multicolumn{4}{|l|}{ Age } \\
\hline$<21$ & $143(0.8 \%)$ & $78(0.8 \%)$ & \multirow[t]{8}{*}{0.9957} \\
\hline 21 to 30 & 1855 (10.5\%) & 1063 (10.7\%) & \\
\hline 31 to 40 & $3553(20.0 \%)$ & 1993 (20.1\%) & \\
\hline 41 to 50 & 3876 (21.9\%) & 2135 (21.5\%) & \\
\hline 51 to 60 & $4545(25.6 \%)$ & $2562(25.8 \%)$ & \\
\hline 61 to 70 & $2527(14.3 \%)$ & $1414(14.3 \%)$ & \\
\hline 71 to 80 & $891(5.0 \%)$ & $491(5.0 \%)$ & \\
\hline$>80$ & $342(1.9 \%)$ & $189(1.9 \%)$ & \\
\hline \multicolumn{4}{|l|}{ Sex } \\
\hline Female & $8054(45.4 \%)$ & $4462(45.0 \%)$ & \multirow[t]{2}{*}{0.4576} \\
\hline Male & 9678 (54.6\%) & $5463(55.0 \%)$ & \\
\hline \multicolumn{4}{|c|}{ Nearest Census based neighborhood income quintile } \\
\hline 1 & $3963(22.4 \%)$ & $2212(22.3 \%)$ & \multirow[t]{5}{*}{0.9939} \\
\hline 2 & 3785 (21.4\%) & $2103(21.2 \%)$ & \\
\hline 3 & 3347 (18.9\%) & $1893(19.1 \%)$ & \\
\hline 4 & 3490 (19.7\%) & 1959 (19.7\%) & \\
\hline 5 & 3147 (17.8\%) & 1758 (17.7\%) & \\
\hline Rural & $1891(10.7 \%)$ & 797 (8.0\%) & $<0.0001$ \\
\hline \multicolumn{4}{|l|}{ Diagnosis codes } \\
\hline Diabetes & $1945(11.0 \%)$ & $1132(11.4 \%)$ & 0.2680 \\
\hline Congestive heart & $97(0.6 \%)$ & $64(0.6 \%)$ & 0.3051 \\
\hline \multicolumn{4}{|l|}{ failure } \\
\hline COPD & $2028(11.4 \%)$ & $1187(12.0 \%)$ & 0.1933 \\
\hline Asthma & 3438 (19.4\%) & 1965 (19.8\%) & 0.4096 \\
\hline Cancer & $1250(7.1 \%)$ & $726(7.3 \%)$ & 0.4110 \\
\hline Musculoskeletal & 7791 (43.9\%) & 4377 (44.1\%) & 0.7931 \\
\hline \multicolumn{4}{|l|}{ issues } \\
\hline Neurologic disorders & 2564 (14.5\%) & $1515(15.3 \%)$ & 0.0702 \\
\hline Pain & $401(2.3 \%)$ & $280(2.8 \%)$ & 0.0040 \\
\hline Behavioural issues & 3313 (18.7\%) & 1929 (19.4\%) & 0.1259 \\
\hline Fatigue & $188(1.1 \%)$ & $139(1.4 \%)$ & 0.0120 \\
\hline Metabolic disease & $2132(12.0 \%)$ & $1286(13 \%)$ & 0.0236 \\
\hline Anxiety at baseline & $4313(24.3 \%)$ & $4867(49.0 \%)$ & $<0.0001$ \\
\hline \multicolumn{4}{|c|}{$\begin{array}{l}\text { *29153 adult patients were identified and subsequently linked to the administrative databases of the Ontario Ministry of Health providing up to at least } 6 \\
\text { months of longitudinal follow-up data following the initial medical cannabis consultation. All data was released as de-identified data. }\end{array}$} \\
\hline \multicolumn{4}{|l|}{ Legend: } \\
\hline COPD: Chronic obstructi & & & \\
\hline
\end{tabular}


Table 2

Cannabis motor vehicle crash healthcare utilization - six months before and six months after authorization for medical cannabis

\begin{tabular}{|c|c|c|c|c|c|c|}
\hline \multirow[t]{3}{*}{ Outcome } & \multicolumn{3}{|c|}{ Cannabis Population } & \multicolumn{3}{|c|}{ Matched Controls (mean) } \\
\hline & \multicolumn{3}{|c|}{$\begin{array}{l}\text { Difference in mean number of visits/admissions per } 10 \\
000 \text { patients from } 6 \text { months before to } 6 \text { months after } \\
\text { medical cannabis }\end{array}$} & \multicolumn{3}{|c|}{$\begin{array}{l}\text { Difference in mean number of visits/admissions per } \\
10000 \text { patients from } 6 \text { months prior to } 6 \text { months } \\
\text { after index date }\end{array}$} \\
\hline & Before & After & Change & Before & After & Change \\
\hline $\begin{array}{l}\text { Hospitalization or Emergency } \\
\text { Department visit as a result of } \\
\text { motor vehicle crashes }\end{array}$ & 46 & 48 & +2 & 32 & 34 & +2 \\
\hline $\begin{array}{l}\text { Hospitalization visit as a result of } \\
\text { motor vehicle crashes }\end{array}$ & 6.05 & 2.02 & -4.03 & 2.82 & 0.56 & -2.26 \\
\hline $\begin{array}{l}\text { Emergency Department visit as a } \\
\text { result of motor vehicle crashes }\end{array}$ & 40 & 46 & +6 & 29 & 33 & +4 \\
\hline
\end{tabular}

Table 3

Interrupted time series analysis of healthcare utilization due to motor vehicle crash six months before and six months after authorization of medical cannabis compared to those unauthorized $(n=27657)$

\begin{tabular}{|c|c|c|c|c|c|c|c|c|c|c|c|c|}
\hline \multirow[t]{4}{*}{ Outcome } & \multicolumn{4}{|c|}{ Authorized } & \multicolumn{4}{|l|}{ Unauthorized } & \multicolumn{4}{|c|}{ Difference } \\
\hline & \multicolumn{2}{|c|}{$\begin{array}{l}\text { Immediate } \\
\text { change* }^{\star}\end{array}$} & \multicolumn{2}{|c|}{$\begin{array}{l}\text { Temporal } \\
\text { change }^{\star \star}\end{array}$} & \multicolumn{2}{|c|}{ Immediate change* } & \multicolumn{2}{|l|}{$\begin{array}{l}\text { Temporal } \\
\text { change }\end{array}$} & \multicolumn{2}{|c|}{$\begin{array}{l}\text { Immediate } \\
\text { change* }\end{array}$} & \multicolumn{2}{|l|}{$\begin{array}{l}\text { Temporal } \\
\text { change }^{\star \star}\end{array}$} \\
\hline & & $\begin{array}{l}\mathrm{p}- \\
\text { value }\end{array}$ & & $\begin{array}{l}\mathrm{p}- \\
\text { value }\end{array}$ & $\begin{array}{l}\text { Events } / 10,000 \\
\text { patients }\end{array}$ & $\begin{array}{l}\mathrm{p}- \\
\text { value }\end{array}$ & & $\begin{array}{l}\mathrm{p}- \\
\text { value }\end{array}$ & Events/ & $\begin{array}{l}\mathrm{p}- \\
\text { value }\end{array}$ & Events/ & $\begin{array}{l}\text { P- } \\
\text { value }\end{array}$ \\
\hline & $\begin{array}{l}10,000 \\
\text { patients }\end{array}$ & & $\begin{array}{l}10,000 \\
\text { patients }\end{array}$ & & & & $\begin{array}{l}10,000 \\
\text { patients }\end{array}$ & & $\begin{array}{l}10,000 \\
\text { patients }\end{array}$ & & $\begin{array}{l}10,000 \\
\text { patients }\end{array}$ & \\
\hline $\begin{array}{l}\text { Motor-vehicle } \\
\text { related } \\
\text { hospitalization } \\
\text { or ER visit }\end{array}$ & -3.15 & 0.3988 & 0.50 & 0.61 & -2.38 & 0.2879 & -0.31 & 0.64 & -2.42 & 0.0138 & 0.89 & 0.0019 \\
\hline $\begin{array}{l}\text { Motor-vehicle } \\
\text { related } \\
\text { hospitalization }\end{array}$ & -1.97 & 0.0365 & 0.22 & 0.2753 & -0.91 & 0.0749 & -0.068 & 0.5782 & -1.10 & 0.7322 & -0.0081 & 0.9898 \\
\hline $\begin{array}{l}\text { Motor-vehicle } \\
\text { related ED }\end{array}$ & -1.91 & 0.5108 & 0.64 & 0.4184 & -1.42 & 0.4661 & -0.18 & 0.7384 & -0.90 & 0.2907 & 0.80 & 0.0001 \\
\hline \multicolumn{13}{|c|}{ *change in the month following the authorization of cannabis or the index date } \\
\hline \multicolumn{13}{|c|}{${ }^{* *}$ change in slope in the six months following the authorization of cannabis or the index date. } \\
\hline \multicolumn{13}{|l|}{ Legend: } \\
\hline \multicolumn{13}{|c|}{ ER: Emergency room } \\
\hline \multicolumn{13}{|c|}{ ED: Emergency department } \\
\hline
\end{tabular}

Table 4

Cannabis motor vehicle crash healthcare utilization - one year before and one year after authorization for medical cannabis

\begin{tabular}{|c|c|c|c|c|c|c|}
\hline \multirow[t]{3}{*}{ Outcome } & \multicolumn{3}{|c|}{ Cannabis Population } & \multicolumn{3}{|c|}{ Matched Controls (mean) } \\
\hline & \multicolumn{3}{|c|}{$\begin{array}{l}\text { Difference in mean number of visits/admissions per } 10 \\
000 \text { patients from } 1 \text { year before to } 1 \text { year after medical } \\
\text { cannabis }\end{array}$} & \multicolumn{3}{|c|}{$\begin{array}{l}\text { Difference in mean number of visits/admissions per } \\
10000 \text { patients from } 1 \text { year prior to } 1 \text { year after } \\
\text { index date }\end{array}$} \\
\hline & Before & After & Change & Before & After & Change \\
\hline $\begin{array}{l}\text { Hospitalization or Emergency } \\
\text { Department visit as a result of motor } \\
\text { vehicle crashes }\end{array}$ & 121 & 95 & -26 & 65 & 50 & -15 \\
\hline $\begin{array}{l}\text { Hospitalization visit as a result of } \\
\text { motor vehicle crashes }\end{array}$ & 3.3 & 9.8 & +6.5 & 0 & 2.5 & +2.5 \\
\hline $\begin{array}{l}\text { Emergency Department visit as a } \\
\text { result of motor vehicle crashes }\end{array}$ & 118 & 85 & -33 & 65 & 47 & -18 \\
\hline
\end{tabular}


Table 5

Interrupted time series analysis of healthcare utilization due to motor vehicle crash one year before and one year after authorization for medical cannabis compared to those unauthorized ( $\mathrm{n}=7065)$

\begin{tabular}{|c|c|c|c|c|c|c|c|c|c|c|c|c|}
\hline \multirow[t]{4}{*}{ Outcome } & \multicolumn{4}{|c|}{ Authorized } & \multicolumn{4}{|l|}{ Unauthorized } & \multicolumn{4}{|c|}{ Difference } \\
\hline & \multicolumn{2}{|c|}{$\begin{array}{l}\text { Immediate } \\
\text { change* }\end{array}$} & \multicolumn{2}{|l|}{ 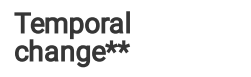 } & \multicolumn{2}{|c|}{ Immediate change* } & \multicolumn{2}{|l|}{$\begin{array}{l}\text { Temporal } \\
\text { change }\end{array}$} & \multicolumn{2}{|c|}{$\begin{array}{l}\text { Immediate } \\
\text { change* }\end{array}$} & \multicolumn{2}{|c|}{$\begin{array}{l}\text { Temporal } \\
\text { change }\end{array}$} \\
\hline & Events/ & $\mathrm{p}-$ & Events/ & p- & Events/10,000 & p- & Events/ & p- & Events/ & $\mathrm{p}-$ & Events/ & P-value \\
\hline & $\begin{array}{l}10,000 \\
\text { patients }\end{array}$ & & $\begin{array}{l}10,000 \\
\text { patients }\end{array}$ & & & & $\begin{array}{l}10,000 \\
\text { patients }\end{array}$ & & $\begin{array}{l}10,000 \\
\text { patients }\end{array}$ & & $\begin{array}{l}10,000 \\
\text { patients }\end{array}$ & \\
\hline $\begin{array}{l}\text { Motor-vehicle } \\
\text { related } \\
\text { hospitalization } \\
\text { or ER visit }\end{array}$ & 4.19 & 0.0294 & 0.33 & 0.1731 & -0.84 & 0.7191 & 0.21 & 0.5973 & 4.77 & 0.0034 & -0.11 & 0.5627 \\
\hline $\begin{array}{l}\text { Motor-vehicle } \\
\text { related } \\
\text { hospitalization }\end{array}$ & 0.040 & 0.9728 & 0.15 & 0.3594 & 0.28 & 0.5182 & -0.0082 & 0.8915 & -0.24 & 0.8662 & 0.19 & 0.6389 \\
\hline $\begin{array}{l}\text { Motor-vehicle } \\
\text { related ED }\end{array}$ & 4.82 & 0.0705 & 0.27 & 0.4309 & -0.84 & 0.7191 & 0.21 & 0.5973 & 3.37 & 0.5935 & 0.23 & 0.7575 \\
\hline \multicolumn{13}{|c|}{ *change in the month following the authorization of cannabis or the index date } \\
\hline \multicolumn{13}{|c|}{${ }^{* *}$ change in slope in the six months following the authorization of cannabis or the index date } \\
\hline \multicolumn{13}{|l|}{ Legend: } \\
\hline \multicolumn{13}{|c|}{ ER: Emergency room } \\
\hline \multicolumn{13}{|c|}{ ED: Emergency department } \\
\hline
\end{tabular}

\section{Figures}




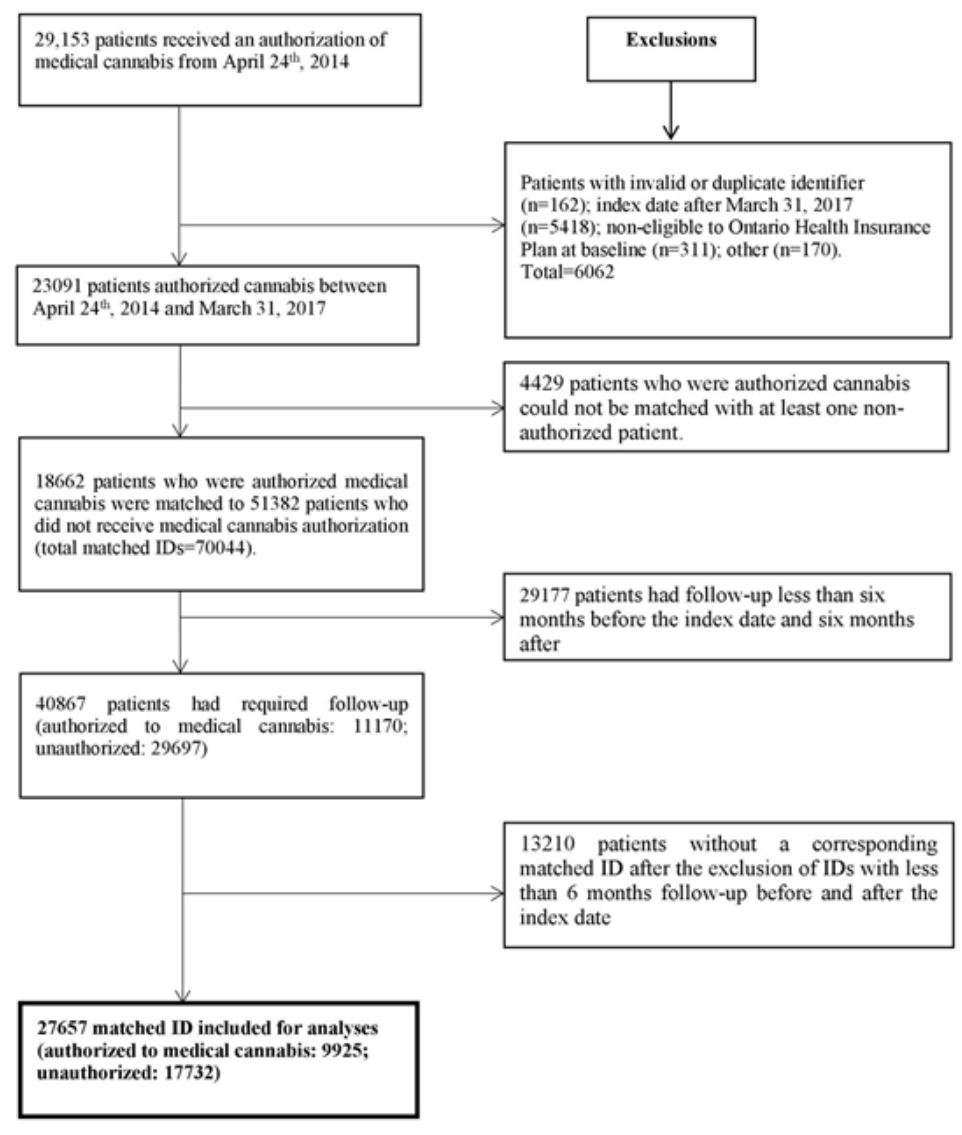

Figure 1

Selection of study population 


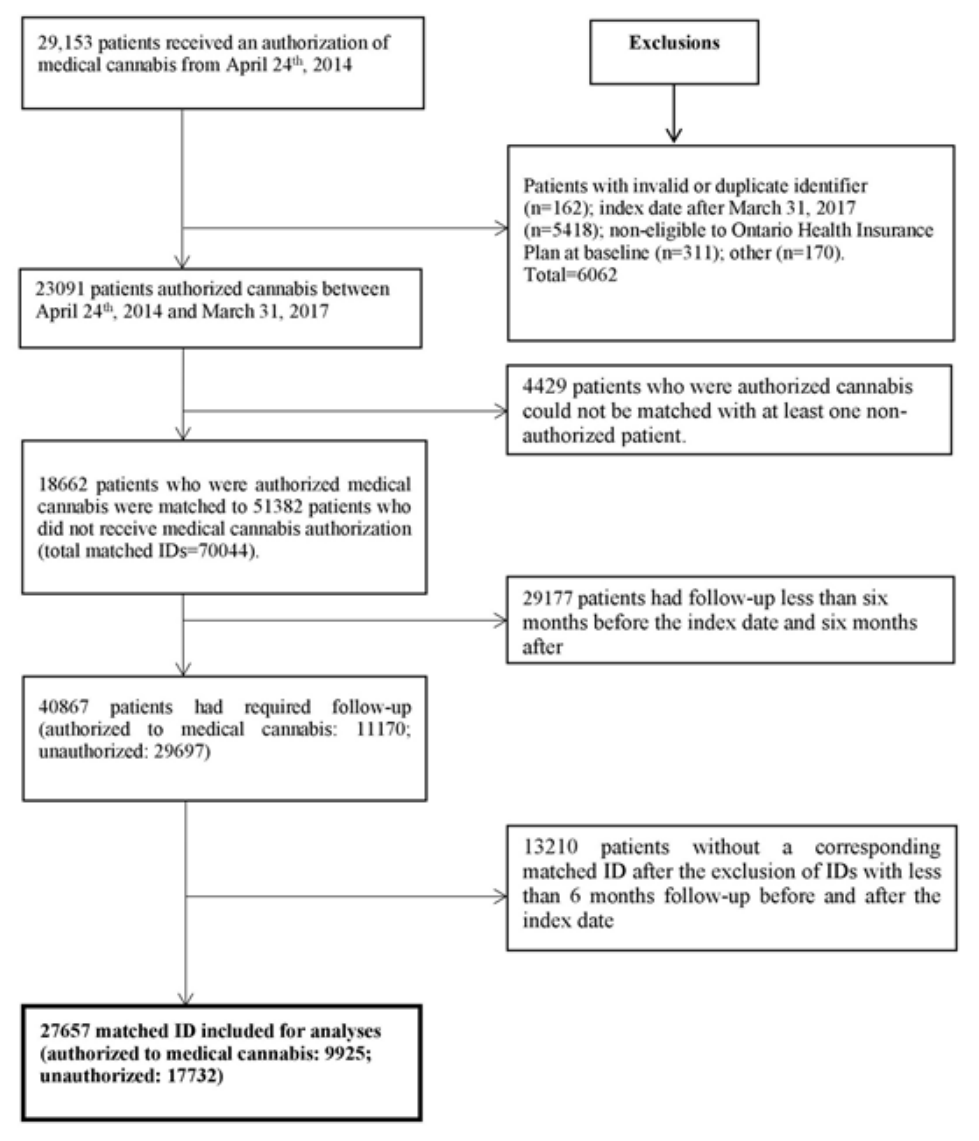

Figure 1

Selection of study population

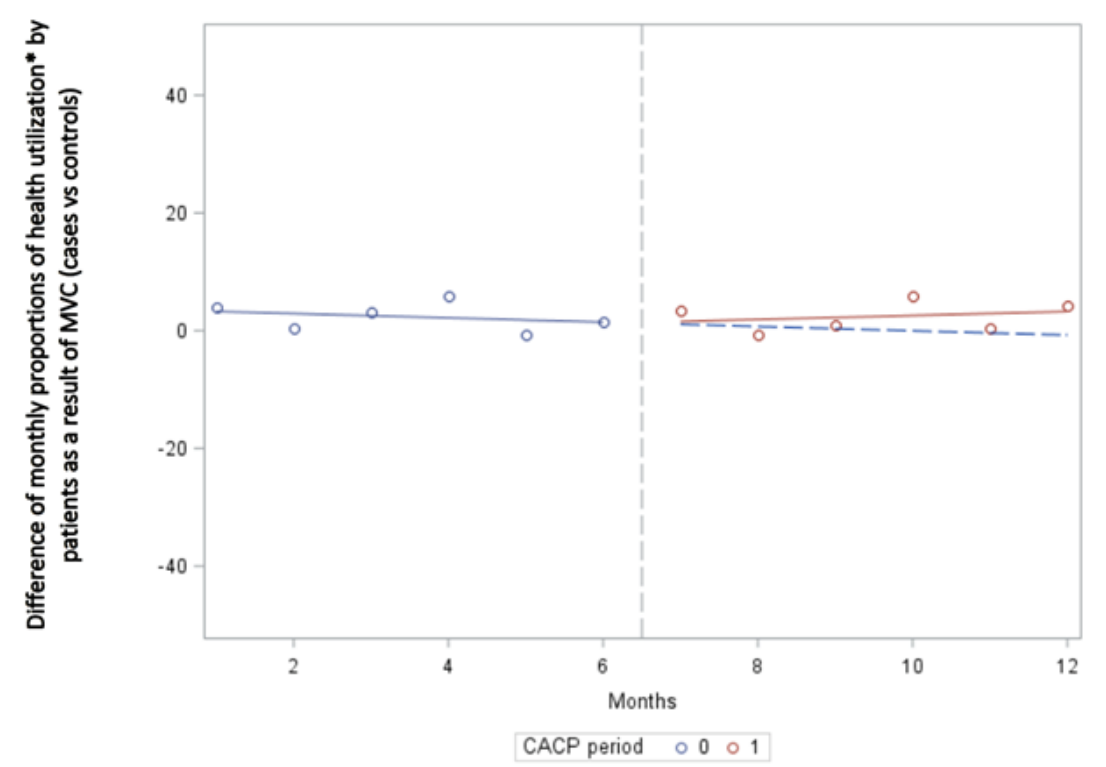

Figure 2

Interrupted Time Series Analyses: Difference in monthly proportion of health care utilization by patients as a result of a motor vehicle crash after authorization of medical cannabis compared to those unauthorized $(n=27657)$ *Healthcare utilization includes all hospitalizations and hospital visits. 


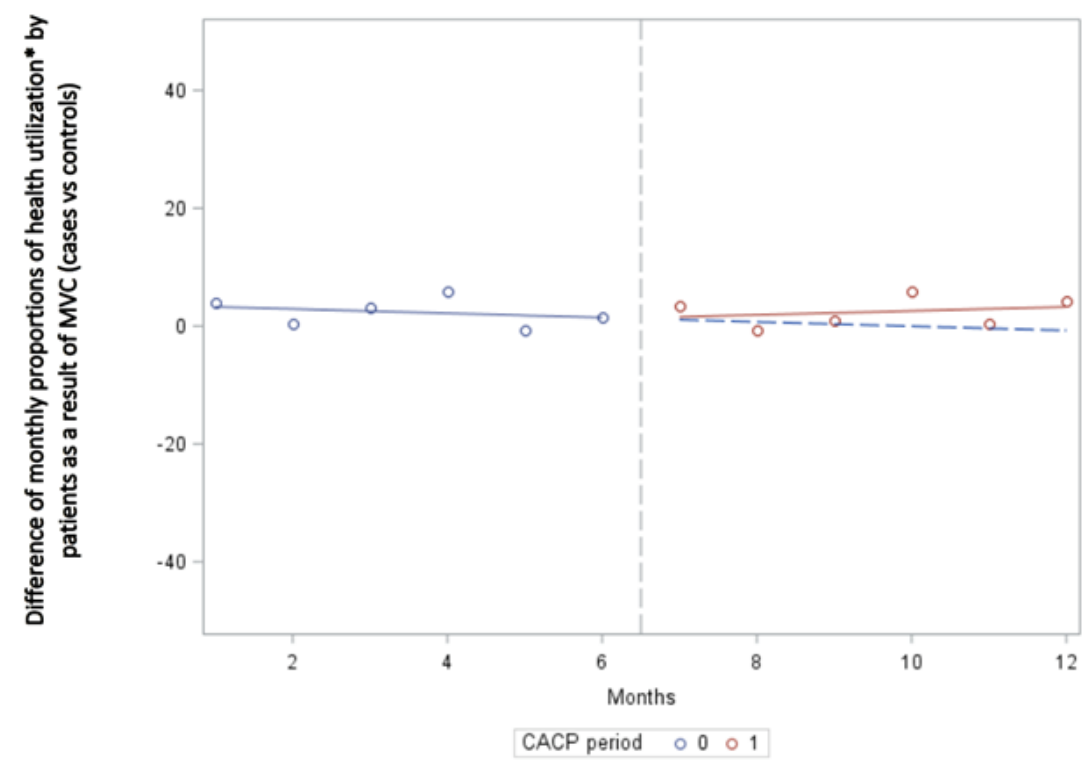

Figure 2

Interrupted Time Series Analyses: Difference in monthly proportion of health care utilization by patients as a result of a motor vehicle crash after authorization of medical cannabis compared to those unauthorized $(n=27657)$ *Healthcare utilization includes all hospitalizations and hospital visits.

\section{Supplementary Files}

This is a list of supplementary files associated with this preprint. Click to download.

- Appendix.docx

- Appendix.docx 